Review

\title{
Clinical Development of c-MET Inhibition in Hepatocellular Carcinoma
}

\section{Joycelyn J. X. Lee ${ }^{\dagger}$, Jack J. Chan ${ }^{\dagger}$ and Su Pin Choo *}

Division of Medical Oncology, National Cancer Centre Singapore, 11 Hospital Drive, Singapore 169610, Singapore; E-Mails: joycelyn.lee.j.x@nccs.com.sg (J.J.X.L.); jack.chan.j.j@nccs.com.sg (J.J.C.)

$\dagger$ These authors contributed equally to this work.

* Author to whom correspondence should be addressed; E-Mail: choo.su.pin@nccs.com.sg; Tel.: +65-64368000; Fax: +65-62252759.

Academic Editor: Stephen L. Chan

Received: 28 August 2015 / Accepted: 21 October 2015 / Published: 28 October 2015

\begin{abstract}
Hepatocellular carcinoma (HCC) is one of the leading causes of cancer death. In patients with advanced or unresectable $\mathrm{HCC}$, there are few treatment options. Conventional chemotherapy has limited benefits. Sorafenib, a multi-kinase inhibitor, improves survival, but options for patients intolerant of or progressing on sorafenib are limited. There has been much interest in recent years in molecular therapeutic targets and drug development for HCC. One of the more promising molecular targets in HCC is the cellular-mesenchymal-epithelial transition (c-MET) factor receptor. Encouraging phase II data on two c-MET inhibitors, tivantinib and cabozantinib, has led to phase III trials. This review describes the c-MET/hepatocyte growth factor (HGF) signalling pathway and its relevance to $\mathrm{HCC}$, and discusses the preclinical and clinical trial data for inhibitors of this pathway in HCC.
\end{abstract}

Keywords: hepatocellular carcinoma (HCC); c-MET; hepatocyte growth factor (HGF); c-MET inhibitor; tivantinib; cabozantinib 


\section{Introduction}

Hepatocellular carcinoma (HCC) is the second leading cause of cancer-related death worldwide [1]. Treatment options in advanced HCC are limited, with conventional chemotherapy having limited efficacy. The multi-kinase inhibitor, sorafenib, was established as the standard of care in patients with advanced HCC after two randomised trials showed a significant survival benefit [2,3], but its use is generally limited to those with good hepatic reserves, and five-year survival remains dismal at less than $10 \%$. Outside of clinical trials, there is a dearth of approved therapeutic options for patients who have disease progression on sorafenib.

At least three recent phase III trials of molecularly targeted agents as second-line treatment in HCC failed to meet their primary endpoints. These trials studied brivanib (BRISK-PS) [4], everolimus (EVOLVE-1) [5], and ramucirumab (REACH) [6] compared to placebo.

The tyrosine kinase receptor, cellular-mesenchymal-epithelial transition (c-MET) factor receptor, has been studied as a potential therapeutic target, and phase II data with the c-MET inhibitors, tivantinib and cabozantinib, have been encouraging, prompting ongoing phase III trials.

In this review, we discuss the c-MET/HGF pathway, its relevance to $\mathrm{HCC}$, and summarise the preclinical and clinical data to date regarding c-MET inhibitors in HCC.

\section{2. c-MET Pathway and Relevance in HCC}

\subsection{The HGF/c-MET Pathway}

The MET proto-oncogene was first identified in an osteosarcoma cell line [7]. The gene encodes for a transmembrane receptor tyrosine kinase (RTK), also known as c-MET, for which HGF is a ligand [8].

Binding of HGF to c-MET's Sema domain leads to receptor homodimerisation, autophosphorylation of tyrosine residues in the tyrosine kinase domain, and downstream activation of the Ras/MAPK, $\mathrm{PI} 3 \mathrm{~K} / \mathrm{Akt}$, and Ras/Rac/Pho pathways [9]. These promote cell proliferation, survival, migration, and angiogenesis [10].

\subsection{Abnormalities in HGF/c-MET Signalling Pathways in Cancer}

Abnormal activation of HGF/c-MET signalling can occur in several ways [11,12]:

\section{(1) Overexpression of HGF}

Elevation of HGF protein levels, both intratumoural and systemic, has been noted in many tumour types, such as lung cancer (50\%), breast cancer (91\%), stomach cancer (87\%), colon cancer (95\%), cancer of the head and neck (45\%) and liver cancer (33\%) [13]. Elevated plasma levels of HGF have been suggested to correlate with a poor prognosis for several forms of cancer, including HCC [14].

Plasma HGF levels have been consistently shown to be higher in patients with HCC compared to controls. Biomarker analyses using samples from the SHARP trial [2] and phase II trial for tivantinib [15,16] suggest that HGF levels may have prognostic significance, with better survival in patients with lower levels, and decreasing levels suggesting disease response. 
(2) Overexpression of c-MET

Overexpression of c-MET in tumour tissue has been noted in many cancers, such as lung cancer, stomach cancer, breast cancer, kidney cancer, colon cancer, and HCC.

In HCC, high c-MET expression has also been found to be a poor prognostic marker, correlating with poorly differentiated tumours and lower survival rates $[15,16]$. Tumour c-MET expression was also predictive of response to tivantinib.

(3) MET amplification

High MET gene copy number can be due to general ploidy status, or true focal gene amplification. MET amplification is less common than overexpression of the protein receptor tyrosine kinase [17], but has been noted primarily in gastrointestinal cancers such as gastric cancer, oesophageal cancer [18] and colon cancer, as well as in endometrial carcinoma, medulloblastoma, non-small cell lung cancer (NSCLC) [19] and gliomas [20].

(4) Activating mutations

Activating mutations in c-MET's tyrosine kinase domain have been reported in hereditary and sporadic papillary renal cell carcinomas [21], paediatric liver cancer and squamous cell carcinoma of the head and neck. Other mutations within c-MET's juxtamembrane region or its Sema domain, where HGF binds, have also been noted in gastric cancer, breast cancer, pleural mesothelioma, and small-cell lung cancer. In addition, c-MET also interacts with other key oncogenic signalling pathways [22].

The interaction between c-MET and HER2 family members is well-documented. MET amplification has been reported to lead to EGFR tyrosine kinase inhibitor (TKI) resistance by HER3-mediated activation of PI3K/AKT signalling in NSCLC [23,24]. MET amplification has also been reported as a mechanism for resistance for colorectal cancer patients treated with anti-EGFR antibodies $[25,26]$.

c-MET/HGF signalling promotes angiogenesis through increasing vascular endothelial growth factor (VEGF)-A expression and interaction with the VEGF receptor (VEGFR) pathway [27]. It has also been shown to maintain the stem cell niche in cancer, with WNT activity in colorectal cancer stem cells described to be supported by myofibroblast-secreted HGF [28].

\section{Overview of HGF/c-MET Pathway Inhibitors}

Small molecule c-MET inhibitors can be classified as selective inhibitors, which specifically target c-MET tyrosine kinase in an ATP-competitive or non-competitive manner, or non-selective inhibitors, which target other kinases in addition to c-MET.

Alternatively, blockade of the HGF/c-MET pathway can also be effected through anti-HGF neutralising antibodies, which block only HGF-dependent c-MET activation, or anti-MET antibodies (Table 1, Figure 1). Anti-HGF antibodies will not be discussed further in this paper owing to a lack of reported signal of activity in HCC. 
Table 1. Classification of HGF/c-MET Inhibitors.

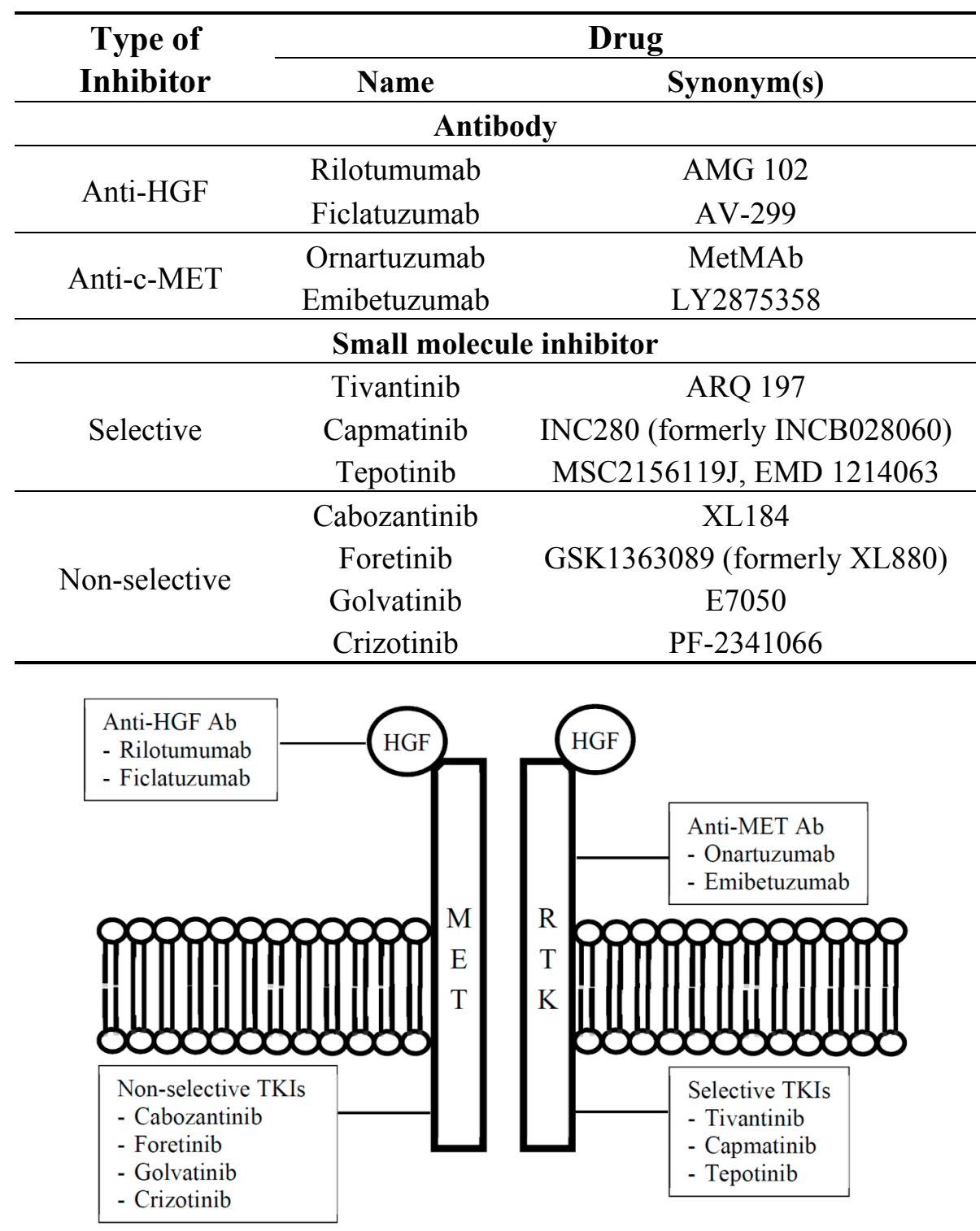

Figure 1. Classification of HGF/c-MET inhibitors.

\section{Preclinical Studies of c-MET Inhibitors in HCC}

Studies have shown the role of HGF in enhancing liver regeneration, hepatocyte survival and tissue remodelling after acute injury [29], and in suppressing hepatocyte apoptosis [28].

In human HCC cell lines, c-MET positive cells were noted to have cancer stem cell-like characteristics. Treated with c-MET inhibition however, c-MET positive cells had increased apoptosis, decreased proliferation and suppressed tumour growth, while c-MET reduced cells survived the inhibition treatment. This suggests that c-MET inhibition may be an effective therapy only for selected patients with strong c-MET expression [30].

c-MET pathway activation is also postulated to promote cancer metastasis by inducing epithelial-tomesenchymal transition (EMT) [31], which causes epithelial cells to lose E-cadherin and cell-to-cell contact and acquire mesenchymal characteristics such as motility and invasion. HGF treatment has been found in murine models of HCC to induce EMT and sustain a mesenchymal phenotype [32]. 


\section{Clinical Studies of c-MET Inhibitors in HCC}

c-MET inhibitors are sequenced in this section by how extensively they have been investigated in HCC, in descending order. Selected active clinical trials involving these agents are summarised in Table 2.

Table 2. Selected Active Clinical Trials on c-MET inhibitors for HCC.

\begin{tabular}{|c|c|c|c|c|}
\hline Drugs & Phase & Patient Selection & Trial Status & $\begin{array}{l}\text { ClinicalTrials.gov } \\
\text { Identifier }\end{array}$ \\
\hline \multicolumn{5}{|l|}{ Tivantinib (ARQ 197) } \\
\hline Monotherapy & $\mathrm{I}$ & Advanced solid tumours $^{\dagger}$ & Recruiting & NCT02150733 \\
\hline With bevacizumab & I & Advanced solid tumours & Active, not recruiting & NCT01749384 \\
\hline With temsirolimus & I & Advanced solid tumours & Recruiting & NCT01625156 \\
\hline With topotecan & I & Advanced solid tumours & Active, not recruiting & NCT01654965 \\
\hline Tivantinib vs. Placebo & III & MET-high HCC & Recruiting & NCT02029157 \\
\hline Tivantinib vs. Placebo & III & MET-high HCC & Recruiting & NCT01755767 \\
\hline \multicolumn{5}{|l|}{ Cabozantinib (XL 184) } \\
\hline Cabozantinib vs. Placebo & III & $\mathrm{HCC}$ & Recruiting & NCT01908426 \\
\hline \multicolumn{5}{|l|}{ Capmatinib (INC280) } \\
\hline Monotherapy & I & Advanced solid tumours & Recruiting & NCT01546428 \\
\hline Monotherapy & I & MET-dysregulated solid tumours & Recruiting & NCT01324479 \\
\hline Monotherapy & II & MET-dysregulated HCC (1st line) & Recruiting & NCT01737827 \\
\hline \multicolumn{5}{|c|}{ Tepotinib (MSC2156119J, EMD 1214063) } \\
\hline Monotherapy & I & Advanced solid tumours & Active, not recruiting & NCT01014936 \\
\hline Monotherapy & $\mathrm{Ib} / \mathrm{II}$ & MET + HCC (1st line $) *$ & Recruiting & NCT01988493 \\
\hline Monotherapy & $\mathrm{Ib} / \mathrm{II}$ & $\mathrm{MET}+\mathrm{HCC}$ & Recruiting & NCT02115373 \\
\hline \multicolumn{5}{|l|}{ Golvatinib (E7050) } \\
\hline With sorafenib & $\mathrm{Ib} / \mathrm{II}$ & $\mathrm{HCC}(1 \text { st line })^{\S}$ & Active, not recruiting & NCT01271504 \\
\hline \multicolumn{5}{|l|}{ Onartuzumab (MetMAb) } \\
\hline Monotherapy & $\mathrm{I}$ & Advanced solid tumours & Recruiting & NCT02031731 \\
\hline \multicolumn{5}{|c|}{ Emibetuzumab (LY2875358) } \\
\hline Monotherapy & $\mathrm{I}$ & Advanced solid tumours & Active, not recruiting & NCT01287546 \\
\hline With Ramucirumab & $\mathrm{Ib} / \mathrm{II}$ & Advanced solid tumours & Recruiting & NCT02082210 \\
\hline
\end{tabular}

All trials are for second-line therapy of advanced HCC unless otherwise indicated. ${ }^{\dagger}$ Restricted to patients with hepatic impairment; * Randomised against sorafenib; § Phase II portion of study randomised against sorafenib alone.

\subsection{Tivantinib (ARQ 197)}

Tivantinib is an oral non-ATP-competitive selective small molecular inhibitor of c-MET. Binding of tivantinib to c-MET stabilises the receptor in its inactive conformation, hence blocking both ligand-dependent and ligand-independent receptor phosphorylation and thus reducing downstream signalling $[33,34]$. Tivantinib demonstrated anti-tumour activity in a wide range of tumour cell lines, as well as in xenograft models [34].

\subsubsection{Phase I Studies}

Phase I studies for tivantinib, both as monotherapy [35-37] and as combination therapy with gemcitabine [38], erlotinib [39] and sorafenib [40], have been conducted in advanced solid tumours. 
The mechanism of action of tivantinib has been questioned preclinically but Yap et al. showed that c-MET decreases in tumours treated with tivantinib [36].

In the phase Ib trial by Santoro et al. [41], tivantinib monotherapy was studied in previously treated HCC patients with Child-Pugh A or B liver cirrhosis. Notably, liver function did not worsen in these patients. Aside from a higher rate of neutropaenia (any grade 52\%, grade 3/4 38\%), tivantinib demonstrated a manageable safety profile. Out of 21 patients, none achieved any objective response, though nine achieved the best response of stable disease.

The combination of tivantinib and sorafenib was examined in a phase I study of 20 HCC patients by Martell et al. [40], following the report of synergistic anti-proliferative activity with the combination in preclinical studies [42]. Of note, eight patients in the study had received sorafenib and/or sunitinib previously, and five achieved stable disease or better. The aforementioned trials suggest that tivantinib may be a promising second-line treatment for advanced HCC.

Chai et al. performed a pooled analysis to summarise the outcomes of 53 patients with HCC or biliary tract cancer receiving tivantinib in phase I trials [43]. These included 23 patients receiving tivantinib monotherapy and 30 patients receiving tivantinib in combination with a second drug. The overall response rate (ORR) and disease control rate (DCR) were $6 \%$ and $62 \%$, respectively.

\subsubsection{Phase II Study}

Based on the phase I data, tivantinib was studied as a second-line therapy for advanced HCC compared against placebo in a randomised multi-centre phase II trial in 107 patients with Child-Pugh A cirrhosis [15]. All of the patients had previously received sorafenib, except for four who had received sunitinib, and had progressed on or did not tolerate first-line treatment. Crossover to open-label tivantinib was allowed for patients on placebo at radiological progression. Of note, the initial dose of tivantinib was planned for $360 \mathrm{mg}$ twice daily, but this was decreased to $240 \mathrm{mg}$ twice daily after 57 patients were enrolled because of a high incidence of grade 3 and 4 neutropaenia. In the whole population, the trial met its primary end point as tivantinib improved time to tumour progression (TTP) (1.6 month vs. 1.4 month; hazard ratio, HR 0.64). Progression-free survival (PFS) and overall survival (OS) however were not statistically different.

Pre-specified subgroup analysis according to c-MET expression status was performed, with MET-high defined as more than $50 \%$ of HCC cells with $2+$ or stronger staining intensity on immunohistochemistry (IHC) [15]. Only the subgroup of patients with MET-high tumours showed a significant survival benefit with improvement in median TTP (2.7 months vs. 1.4 month; HR 0.43; 95\% CI 0.18-0.81), median PFS (2.2 months vs. 1.4 month; HR 0.45; 95\% CI 0.21-0.95) and median OS (7.2 months vs. 3.8 months; HR $0.38 ; 95 \%$ CI $0.18-0.81$ ). The survival advantage for patients on the lower dose of $240 \mathrm{mg}$ twice daily of tivantinib was at least equivalent to that observed among patients on the higher dose of $360 \mathrm{mg}$ twice daily. Among MET-low patients, however, there was no difference in response rates or survival outcomes between tivantinib and placebo, suggesting that c-MET expression is predictive of response to tivantinib.

The same authors subsequently showed that the interaction test between treatment and tumour c-MET levels in OS was positive $(p=0.0385)$ [16]. They also found that tumour c-MET was the only biomarker which predicted response to tivantinib.

Selected phase I and II studies of tivantinib monotherapy are summarised in Table 3. 
Table 3. Selected phase I and II clinical trials of Tivantinib monotherapy in HCC (adapted from Rimassa et al. [44]).

\begin{tabular}{|c|c|c|c|c|c|}
\hline Trial & Study Design & Patient Selection & Toxicity Outcomes & Efficacy Outcomes & Dose \\
\hline \multicolumn{6}{|l|}{ Phase I studies } \\
\hline \multirow{2}{*}{$\begin{array}{l}\text { Rosen et al., } \\
\text { (2011) [35] }\end{array}$} & \multirow{2}{*}{ Dose-escalation study } & \multirow{2}{*}{$\begin{array}{l}\text { Advanced solid tumours } \\
(N=79)\end{array}$} & $\begin{array}{l}\text { Most common AE: fatigue (14\%), nausea } \\
(14 \%) \text {, vomiting }(10 \%) \text {, anaemia }(8 \%) \text {, } \\
\text { diarrhoea }(6 \%)\end{array}$ & \multirow{2}{*}{$\begin{array}{l}\text { Three patients }(3.8 \%) \text { achieved PR; } \\
40 \text { patients }(50.6 \%) \text { maintained SD } \\
\text { for a median of } 19.9 \text { weeks }\end{array}$} & \multirow{2}{*}{$\begin{array}{l}\text { MTD not reached } \\
\text { R2PD: } 360 \mathrm{mg} \mathrm{BD}\end{array}$} \\
\hline & & & $\begin{array}{l}\text { DLT: leucopaenia, neutropaenia, } \\
\text { thrombocytopaenia, vomiting, dehydration } \\
\text { in } 2 \text { patients treated with } 360 \mathrm{mg} \mathrm{BD}\end{array}$ & & \\
\hline $\begin{array}{l}\text { Yap et al., } \\
(2011)[36]\end{array}$ & Dose-escalation study & $\begin{array}{l}\text { Advanced solid tumours } \\
(N=51)\end{array}$ & $\begin{array}{l}\text { Most common AE }(>10 \%) \text { : grade } 1 / 2 \text { fatigue } \\
(16 \%) \text {, nausea }(14 \%) \text {, vomiting }(12 \%)\end{array}$ & $\begin{array}{l}\text { Best response of } \mathrm{SD} \geq 4 \text { months } \\
\text { in } 14 \text { patients }(27 \%)\end{array}$ & $\begin{array}{l}\text { MTD/R2PD: } \\
360 \mathrm{mg} \mathrm{BD}\end{array}$ \\
\hline \multirow{4}{*}{$\begin{array}{l}\text { Santoro et al., } \\
(2013)[41]\end{array}$} & \multirow{4}{*}{ Phase Ib study } & \multirow{4}{*}{$\begin{array}{l}\text { HCC }(N=21), \text { including } \\
\text { Child-Pugh A }(N=17) \text { or } \\
\text { B }(N=4) \text { liver cirrhosis }\end{array}$} & No drug-related worsening of liver function & \multirow{4}{*}{$\begin{array}{l}\text { Best response of SD } \\
\text { in nine patients }(43 \%)\end{array}$} & \multirow{4}{*}{ RP2D: $360 \mathrm{mg} \mathrm{BD}$} \\
\hline & & & $\begin{array}{l}\text { Grade } \geq 3 \text { drug-related AEs in } 11 \text { patients } \\
(52 \%) \text {, including neutropaenia in eight } \\
\text { patients }(38 \%)\end{array}$ & & \\
\hline & & & Grade 5 neutropaenic septic shock $(N=1)$ & & \\
\hline & & & $\begin{array}{l}\text { Four cardiac events were considered possibly } \\
\text { or probably related to study drug }\end{array}$ & & \\
\hline \multicolumn{6}{|l|}{ Phase II study } \\
\hline $\begin{array}{l}\text { Santoro et al., } \\
(2013)[15]\end{array}$ & $\begin{array}{l}\text { Placebo-controlled } \\
\text { randomised phase II } \\
\text { study; crossover } \\
\text { allowed at radiologic } \\
\text { PD }(N=23)\end{array}$ & $\begin{array}{l}\text { Advanced HCC }(N=107) \\
\text { failing or intolerant of } \\
\text { first-line systemic therapy } \\
\text { with sorafenib or sunitinib }\end{array}$ & $\begin{array}{l}\text { Most common AE: asthenia }(42 \%) \text {, } \\
\text { loss of appetite }(27 \%) \text {, neutropaenia }(21 \%) \text {, } \\
\text { fatigue }(12 \%)\end{array}$ & $\begin{array}{l}\text { Increased TTP for the ITT population } \\
\text { ( } 6.9 \text { vs. } 6.0 \text { weeks). Greatest clinical } \\
\text { benefit for MET-high patients: TTP } \\
\text { (11.7 vs. } 6.1 \text { weeks), PFS and OS } \\
\text { (7.2 vs. } 3.8 \text { months) }\end{array}$ & $240 \mathrm{mg} \mathrm{BD}$ \\
\hline
\end{tabular}

Abbreviations: PD: progressive disease; AE: adverse events; DLT: dose-limiting toxicities; PR: partial response; SD: stable disease; TTP: time to progression; ITT: intention-to-treat; PFS: progression free survival; OS: overall survival; MTD: maximum tolerated dose; RP2D: recommended phase 2 dose; BD: twice daily. 


\subsubsection{Phase III Studies}

Extending from the phase II data, there are currently two phase III double-blind, randomised controlled trials that are recruiting patients with advanced HCC and high c-MET-expression to compare tivantinib as second-line treatment against placebo, namely the METIV-HCC trial in the West (ClinicalTrials.gov Identifier: NCT01755767) and the JET-HCC trial in Japan (ClinicalTrials.gov Identifier: NCT02029157).

In the METIV-HCC trial, the original dose of $240 \mathrm{mg}$ twice daily was reduced to $120 \mathrm{mg}$ twice daily, after a higher than expected rate of neutropaenia and higher than expected drug exposure levels were observed. These were attributed to the switch in formulation from capsules used in the phase II study to tablets $[45,46]$. The primary endpoint of the trial is OS, with secondary endpoints defined as PFS and safety.

\subsection{Cabozantinib (XL 184)}

Cabozantinib is a non-selective oral multi-kinase inhibitor targeting c-MET, VEGFR2, KIT, RET, FLT3 and TIE-2. Cabozantinib has been shown to prolong survival in a c-MET-driven transgenic mouse model of HCC and to show efficacy against human HCC xenografts grown in mice [47].

\subsubsection{Phase I Study}

A phase I dose-escalation study of cabozantinib in 85 patients with advanced solid tumours established the maximum tolerated dose (MTD) at $175 \mathrm{mg}$ daily [48]. Dose-limiting toxicities (DLT) were hand-foot syndrome, mucositis, and transaminitis. The study included one patient with HCC whose disease was measurable, and in whom cabozantinib attained stable disease for at least three months.

\subsubsection{Phase II Study}

A phase II randomised discontinuation study evaluated cabozantinib in advanced solid tumours of nine different tumour types, including HCC $(N=41)$ [49,50]. The study design incorporated a 12-week "lead-in" treatment period with cabozantinib followed by open-label continued treatment in responders until disease progression, treatment discontinuation in patients with disease progression, and random blinded assignment between cabozantinib and placebo in those with stable disease. The most frequent grade 3 and higher adverse events associated with cabozantinib were hand-foot syndrome (15\%), diarrhoea (9\%), and thrombocytopaenia (9\%). DCR at 12 weeks was $71 \%$ in patients with HCC [50]. Notably, $49 \%$ of these patients were sorafenib-naïve, that is, cabozantinib was the first-line therapy for these patients.

Of note, this study did not evaluate for c-MET expression as a predictor of response to cabozantinib, and given the broad spectrum of targets of cabozantinib, it is unclear how much of the activity is attributable to c-MET inhibition alone. In fact, the combined inhibitory effects of c-MET and VEGF may be particularly effective, which is postulated to be due to upregulated c-MET signalling from VEGF inhibition, either from resultant hypoxia or direct interactions between VEGFR2 and MET [51].

Selected phase I and II studies of cabozantinib monotherapy are summarised in Table 4. 
Table 4. Selected phase I and II clinical trials of Cabozantinib monotherapy in HCC.

\begin{tabular}{|c|c|c|c|c|c|}
\hline Trial & Study Design & Patient Selection & Toxicity Outcomes & Efficacy Outcomes & Dose \\
\hline \multicolumn{6}{|l|}{ Phase I study } \\
\hline $\begin{array}{l}\text { Kuzrock et al., } \\
\text { (2011) [48] }\end{array}$ & $\begin{array}{l}\text { Dose } \\
\text { escalation } \\
\text { study }\end{array}$ & $\begin{array}{l}\text { Advanced solid } \\
\text { tumours }(N=85)\end{array}$ & $\begin{array}{l}\text { DLT: HFS, mucositis, } \\
\text { transaminitis }\end{array}$ & $\begin{array}{l}\text { In one patient with } \mathrm{HCC} \\
\text { whose disease was } \\
\text { measurable, SD for at } \\
\text { least three months }\end{array}$ & $\begin{array}{l}\text { MTD: } \\
175 \mathrm{mg} \text { OD }\end{array}$ \\
\hline \multicolumn{6}{|l|}{ Phase II study } \\
\hline $\begin{array}{l}\text { Cohn et al., } \\
(2012)[50]\end{array}$ & $\begin{array}{l}\text { Randomised } \\
\text { discontinuation } \\
\text { study }\end{array}$ & $\operatorname{HCC}(N=41)$ & $\begin{array}{l}\text { Most common grade } \geq 3 \mathrm{AE}: \\
\text { HFS }(15 \%) \text {, diarrhoea }(9 \%) \text {, } \\
\text { thrombocytopaenia }(9 \%)\end{array}$ & $\begin{array}{l}\text { DCR at } 12 \text { weeks: } 71 \% \\
\text { (Asian subgroup: } 77 \% \text { ) }\end{array}$ & $100 \mathrm{mg}$ OD \\
\hline
\end{tabular}

Abbreviations: DLT: dose-limiting toxicities; HFS: hand foot syndrome; AE: adverse events; SD: stable disease; DCR: disease control rate; MTD: maximum tolerated dose; OD: once daily.

\subsubsection{Phase III Study}

Given the encouraging data from the phase II study, a phase III randomised double-blind study is currently recruiting to compare cabozantinib against placebo as second-line treatment for advanced HCC patients who have previously received sorafenib [52]. Enrolment started in September 2013 with a target recruitment of 760 patients. (ClinicalTrials.gov Identifier: NCT01908426). Endpoints of the study are OS (primary), PFS and ORR (secondary), with two interim analyses and a final analysis planned.

\subsection{Capmatinib (INC280, Formerly INCB028060)}

Capmatinib is a highly selective c-MET inhibitor. It has demonstrated strong dose-dependent anti-tumour activity and dose-dependent reduction of phosphorylated MET (pMET) levels in c-MET-dependent murine tumour models [53].

\subsubsection{Phase I Study}

In a phase I dose-escalation study, capmatinib was tested in 33 patients with confirmed c-MET-dysregulated advanced solid tumours, with HCC representing the commonest tumour type (45\%), which were refractory to current therapy or for which effective therapy was lacking [54]. Stable disease was reported in 8/33 (24\%) of the entire cohort. The recommended phase II dose (RP2D) was $600 \mathrm{mg}$ twice a day, with DLT of fatigue and hyperbilirubinaemia.

\subsubsection{Phase II Studies}

A phase II trial is currently ongoing testing the efficacy and safety of capmatinib as first-line treatment for patients with c-MET-dysregulated advanced HCC (ClinicalTrials.gov Identifier: NCT01737827). The trial is actively recruiting patients.

There was also a phase II randomised trial for capmatinib as second-line treatment for patients with advanced HCC after sorafenib, but the trial was suspended without any patient recruitment (ClinicalTrials.gov Identifier: NCT01964235). 


\subsection{Tepotinib (MSC2156119J, EMD 1214063)}

Tepotinib is a specific, reversible, ATP-competitive c-MET inhibitor.

\subsubsection{Phase I Study}

Following encouraging preclinical data in liver cancer models [55], a phase I study of tepotinib demonstrated good anti-tumour activity and tolerability in patients with advanced solid tumours [56]. DLT were asymptomatic lipase and amylase increases, nausea and vomiting, fatigue, and ALT elevation. The RP2D was $500 \mathrm{mg}$ per day.

\subsubsection{Phase II Studies}

There are currently two phase Ib/II trials ongoing for tepotinib. The first is a single-arm trial evaluating tepotinib as second-line treatment for MET-positive advanced HCC (ClinicalTrials.gov Identifier: NCT02115375). The other trial is a randomised open-label trial comparing tepotinib against sorafenib as upfront treatment in Asian patients with MET-positive advanced HCC (ClinicalTrials.gov Identifier: NCT01988493). MET positivity in the trial is defined as moderate or strong protein overexpression on IHC [57].

\subsection{Foretinib (GSK1363089, Formerly XL880)}

Foretinib is an ATP-competitive TKI with activity against c-MET, AXL, RON, VEGFR2, TIE-2 and PDGFR. It has been shown to inhibit tumour growth and prolong mouse survival in patient-derived HCC xenograft models [58].

\subsubsection{Phase I Study}

A phase I study of foretinib showed DLT of transaminitis and elevated lipase levels, and common adverse events of hypertension, fatigue, diarrhoea and vomiting, proteinuria, and haematuria [59]. The RP2D was $250 \mathrm{mg}$ given on the first five days of a 14-day cycle.

\subsubsection{Phase I/II Study}

Foretinib has been studied as first-line therapy in a phase I/II study in Asian patients with advanced HCC. The phase I portion of the study showed ORR of $24 \%$, disease stabilisation rate of $79 \%$ and median time to progression of 4.2 months, with no DLT observed at $30 \mathrm{mg}$ once daily [60].

\subsection{Golvatinib (E7050)}

Golvatinib is a non-specific c-MET inhibitor, with activity also against VEGFR2, c-KIT and RON. It has been shown to promote tumour regression and prolong survival in mouse xenograft models [61]. 


\subsubsection{Phase I Studies}

Two dose-finding phase I studies were conducted in patients with advanced solid tumours. The Japanese study found that the MTD was $200 \mathrm{mg}$ twice a day [62], while the UK study determined the MTD as $400 \mathrm{mg}$ once daily [63]. The DLT in both studies were similar, being derangements in liver enzymes, fatigue, and nausea and vomiting, with the former study also reporting proteinuria in $50 \%$ of the study cohort.

\subsubsection{Phase Ib/II Study}

A phase Ib/II clinical trial is currently recruiting, in which the phase II cohort will compare golvatinib plus sorafenib against sorafenib alone as first-line use in patients with advanced HCC (ClinicalTrials.gov Identifier: NCT01271504). The phase I portion of the trial suggested that the golvatinib and sorafenib combination had manageable toxicity and showed an encouraging $17 \%$ of patients with partial responses and durable stable disease in another $31 \%$ [64].

\subsection{Onartuzumab (MetMAb)}

Onartuzumab is a monovalent, humanised monoclonal antibody specific for an epitope in the HGF-binding domain of the c-MET receptor. It was developed to overcome the limitation of bivalent antibodies which was thought might cause receptor dimerisation [65]. Onartuzumab forms a stable bond with c-MET on the cellular surface without inducing c-MET internalisation or shedding [66].

Phase I Studies

A phase I dose-escalation study of onartuzumab as a single agent and in combination with bevacizumab was carried out in patients with advanced solid malignancies. The maximum tolerated dose was not reached, while the most common drug-related adverse events included fatigue, peripheral oedema, nausea and hypoalbuminaemia [67]. A second phase I study of onartuzumab in Japanese patients with solid tumours showed no DLT when used alone or in combination with erlotinib [68]. A third phase I study of onartuzumab specific to Chinese patients with advanced or metastatic solid tumour is currently recruiting patients (ClinicalTrials.gov Identifier: NCT02031731).

A phase Ib open-label study evaluating onartuzumab as a single agent and in combination with sorafenib in patients with advanced HCC has completed recruitment (ClinicalTrials.gov Identifier: NCT01897038).

\subsection{Emibetuzumab (LY2875358)}

Emibetuzumab is a bivalent c-MET-specific monoclonal antibody that blocks HGF binding to c-MET, and neutralises and accelerates internalisation and degradation of the c-MET receptor upon binding, decreasing its level of cell surface expression [69]. 


\subsubsection{Phase I Study}

A phase I dose-escalation study of emibetuzumab was performed in advanced solid tumours, establishing a RP2D of $750 \mathrm{mg}$ every 2 weeks [70]. No DLT were observed, with the most frequent adverse effects reported being nausea, vomiting and diarrhoea.

\subsubsection{Phase $\mathrm{Ib} / 2$ Study}

A phase $\mathrm{Ib} / 2$ study examining emibetuzumab in combination with ramucirumab in advanced solid tumours including HCC is actively recruiting (ClinicalTrials.gov Identifier: NCT01602289).

\section{Biomarkers for c-MET-Targeted Therapies}

It is unclear whether systemic levels of HGF predict response to anti-HGF/c-MET therapies. HGF levels are also known to be elevated in many other clinical settings including infections, graft-versus-host disease, and after surgical procedures.

Use of IHC for determination of c-MET protein overexpression has been extensively reviewed [71,72], but the variability among published studies in current literature suggests that standardisation of protocols is warranted [12]. Identifying MET-positive/high patients using IHC has been studied as part of various trials, such as the phase II trials of ornatuzumab or placebo with erlotinib in advanced NSCLC [73], rilotumumab or placebo combined with chemotherapy in advanced gastric or gastric oesophageal cancer [74], and tivantinib or placebo in advanced $\mathrm{HCC}[15,16]$. The three trials defined different IHC cut-off criteria: at least $50 \%$ tumour cells with $2+$ or $3+$ staining was referred to as "MET diagnostic positive" in the ornatuzumab study and "MET-high" in the tivantinib study, whereas the rilotumumab study defined "MET-positive" as at least 25\% membrane staining of tumour cells at any intensity.

Determination of pMET as a biomarker has been used in vitro, but has not been validated in larger studied in histological specimens.

In the onartuzumab trial [73], additional subgroup analyses were performed to determine the effect of MET copy number changes and EGFR mutational status. c-MET IHC was found to correlate with MET FISH, but benefit to c-MET-targeted therapy was seen in patients positive by IHC but negative by FISH. In the same study, pMET expression was also studied, but many cases with moderate to strong signals for c-MET by IHC were negative for pMET, suggesting that pMET is an insufficiently sensitive biomarker. In both studies, high c-MET expression was found to be prognostic, and interestingly, low c-MET expression seemed to be predictive of poorer outcome when treated with targeted therapy, emphasising the need for good assays and biomarkers to select a population suitable for targeted therapies.

Another possible strategy is the assessment of MET sequence status, including MET mutations, MET amplification, and chromosome 7 polysome [75].

Preclinical studies of different c-MET inhibitors revealed variable efficacy based on the specific MET mutation, e.g., PF-2341066/4217903, has greater activity against certain c-MET ATP-binding site mutations compared to c-MET kinase domain activations [76]. One such TKI, SU11274, has also showed selective inhibition for two of four identified MET mutations [77]. MET amplification (defined as MET:CEP7 ratio $\geq 2$ ) has been found to correlate with increased clinical response of metastatic gastric cancer to foretinib in a phase II study [78]; whereas MET copy number (positives scored as $\geq$ four copies 
in $\geq 40 \%$ of cells), to correlate with increased clinical response to tivantinib with erlotinib in advanced NSCLC [79].

\section{Conclusions}

Therapeutic options for patients with advanced HCC intolerant to or progressive on sorafenib are scant. Data from c-MET inhibitors is promising, with phase III trials in progress for tivantinib and cabozantinib.

Considering that preclinical and clinical data suggest that the benefit of c-MET inhibition may be restricted to a patient subpopulation with high c-MET expression, future trials may need to be enriched by prospectively incorporating biomarker analyses to validate this hypothesis, so as to better select patients who would benefit from these therapies. Already, the METIV-HCC trial has adopted such a strategy of enrolling only patients with MET-high HCC, and its results are eagerly awaited.

\section{Author Contributions}

S.P.C. conceptualized and designed the article. J.J.X.L and J.J.C. performed research and wrote the paper. All authors read and approved the final manuscript.

\section{Conflicts of Interest}

S.P.C.: Advisory board/received funding/consulted/speaker for Merck, Sanofi-Aventis, Bristol-Myers Squibb, Norvatis, and Bayer.

\section{References}

1. The global and regional burden of cancer. In World Cancer Report; Steward, B.W., Wild, C.P., Eds.; IARC Press: Lyon, France, 2014; pp. 16-53.

2. Llovet, J.M.; Ricci, S.; Mazzaferro, V.; Hilgard, P.; Gane, E.; Blanc, J.F.; de Oliveira, A.C.; Santoro, A.; Raoul, J.L.; Forner, A. Sorafenib in advanced hepatocellular carcinoma. N. Engl. J. Med. 2008, 359, 378-390.

3. Cheng, A.L.; Kang, Y.K.; Chen, Z.; Tsao, C.J.; Qin, S.; Kim, J.S.; Luo, R.; Feng, J.; Ye, S.; Yang, T.S. Efficacy and safety of sorafenib in patients in the Asia-Pacific region with advanced hepatocellular carcinoma: A phase III randomised, double-blind, placebo-controlled trial. Lancet Oncol. 2009, 10, $25-34$.

4. Llovet, J.M.; Decaens, T.; Raoul, J.L.; Boucher, E.; Kudo, M.; Chang, C.; Kang, Y.K.; Assenat, E.; Lim, H.Y.; Boige, V. Brivanib in patients with advanced hepatocellular carcinoma who were intolerant to sorafenib or for whom sorafenib failed: Results from the randomized phase III brisk-ps study. J. Clin. Oncol. 2013, 31, 3509-3516.

5. Zhu, A.X.; Kudo, M.; Assenat, E.; Cattan, S.; Kang, Y.K.; Lim, H.Y.; Poon, R.T.; Blanc, J.F.; Vogel, A.; Chen, C.L. Effect of everolimus on survival in advanced hepatocellular carcinoma after failure of sorafenib: The EVOLVE-1 randomized clinical trial. JAMA 2014, 312, 57-67.

6. Zhu, A.X.; Park, J.O.; Ryoo, B.Y.; Yen, C.J.; Poon, R.; Pastorelli, D.; Blanc, J.; Chung, H.C.; Baron, A.D.; Pfiffer, T.E. Ramucirumab versus placebo as second-line treatment in patients 
with advanced hepatocellular carcinoma following first-line therapy with sorafenib (REACH): A randomised, double-blind, multicentre, phase 3 trial. Lancet Oncol. 2015, 16, 859-870.

7. Cooper, C.S.; Park, M.; Blair, D.G.; Tainsky, M.A.; Huebner, K.; Croce, C.M.; Vande Woude, G.F. Molecular cloning of a new transforming gene from a chemically transformed human cell line. Nature 1984, 311, 29-33.

8. Bottaro, D.P.; Rubin, J.S.; Faletto, D.L.; Chan, A.M.; Kmiecik, T.E.; Vande Woude, G.F.; Aaronson, S.A. Identification of the hepatocyte growth factor receptor as the c-MET proto-oncogene product. Science 1991, 251, 802-804.

9. Gherardi, E.; Birchmeier, W.; Birchmeier, C.; Vande Woude, G. Targeting MET in cancer: Rationale and progress. Nat. Rev. Cancer 2012, 12, 89-103.

10. Ma, P.C.; Maulik, G.; Christensen, J.; Salgia, R. C-MET: Structure, functions and potential for therapeutic inhibition. Cancer Metastasis Rev. 2003, 22, 309-325.

11. Yano, S.; Nakagawa, T. The current stage of molecularly targeted drugs targeting HGF/MET. Jpn. J. Clin. Oncol. 2014, 44, 9-12.

12. Koeppen, H.; Rost, S.; Yauch, R.L. Developing biomarkers to predict benefit from HGF-MET pathway inhibitors. J. Pathol. 2014, 232, 210-218.

13. Hepatocyte Growth Factor/Scatter Factor (HGF/SF). MET and Cancer References. Available online: http://www.vai.org/Met/Index.aspx (accessed on 26 August 2015).

14. Christensen, J.G.; Burrows, J.; Salgia, R. C-MET as a target for human cancer and characterization of inhibitors for therapeutic intervention. Cancer Lett. 2005, 225, 1-26.

15. Santoro, A.; Rimassa, L.; Borbath, I.; Daniele, B.; Salvagni, S.; van Laethem, J.L.; van Vlierberghe, H.; Trojan, J.; Kolligs, F.; Weiss, A. Tivantinib for second-line treatment of advanced hepatocellular carcinoma: A randomised, placebo-controlled phase 2 study. Lancet Oncol. 2013, 14, 55-63.

16. Rimassa, L.; Abbadessa, G.; Personeni, N.; Porta, C.; Borbath, I.; Daniele, B.; Salvagni, S.; van Laethem, J.L.; van Vlierberghe, H.; Trojan, J. Tivantinib in pretreated hepatocellular carcinoma (HCC): Tumor and plasma biomarker analysis from the randomized controlled phase 2 trial (RCT). In Proceedings of the 9th International Liver Cancer Association Annual Conference, Paris, France, 4 September 2015.

17. Kondo, S.; Ojima, H.; Tsuda, H.; Hashimoto, J.; Morizane, C.; Ikeda, M.; Ueno, H.; Tamura, K.; Shimada, K.; Kanai, Y. Clinical impact of c-MET expression and its gene amplification in hepatocellular carcinoma. Int. J. Clin. Oncol. 2013, 18, 207-213.

18. Lennerz, J.K.; Kwak, E.L.; Ackerman, A.; Michael, M.; Fox, S.B.; Bergethon, K.; Lauwers, G.Y.; Christensen, J.G.; Wilner, K.D.; Haber, D.A. MET amplification identifies a small and aggressive subgroup of esophagogastric adenocarcinoma with evidence of responsiveness to crizotinib. J. Clin. Oncol. 2011, 29, 4803-4810.

19. Ou, S.H.; Kwak, E.L.; Siwak-Tapp, C.; Dy, J.; Bergethon, K.; Clark, J.W.; Camidge, D.R.; Solomon, B.J.; Maki, R.G.; Bang, Y.J. Activity of crizotinib (PF02341066), a dual mesenchymal-epithelial transition (MET) and anaplastic lymphoma kinase (ALK) inhibitor, in a non-small cell lung cancer patient with de novo MET amplification. J. Thorac. Oncol. 2011, 6, 942-946.

20. Chi, A.S.; Batchelor, T.T.; Kwak, E.L.; Clark, J.W.; Wang, D.L.; Wilner, K.D.; Louis, D.N.; Iafrate, A.J. Rapid radiographic and clinical improvement after treatment of a MET-amplified recurrent glioblastoma with a MET inhibitor. J. Clin. Oncol. 2012, 2012, e30-e33. 
21. Schmidt, L.; Duh, F.M.; Chen, F.; Kishida, T.; Glenn, G.; Choyke, P.; Scherer, S.W.; Zhuang, Z.; Lubensky, I.; Dean, M. Germline and somatic mutations in the tyrosine kinase domain of the MET proto-oncogene in papillary renal carcinomas. Nat. Genet. 1997, 16, 68-73.

22. Smyth, E.C.; Sclafani, F.; Cunningham, D. Emerging molecular targets in oncology: Clinical potential of MET/hepatocyte growth-factor inhibitors. Onco Targets Ther. 2014, 12, 1001-1014.

23. Dulak, A.M.; Gubish, C.T.; Stabile, L.P.; Henry, C.; Siegfried, J.M. HGF-independent potentiation of EGFR action by c-MET. Oncogene 2011, 30, 3625-3635.

24. Engelman, J.A.; Zejnullahu, K.; Mitsudomi, T.; Song, Y.; Hyland, C.; Park, J.O.; Lindeman, N.; Gale, C.M.; Zhao, X.; Christensen, J. MET amplification leads to gefitinib resistance in lung cancer by activating erbB3 signaling. Science 2007, 316, 1039-1043.

25. Troiani, T.; Martinelli, E.; Napolitano, S.; Vitagliano, D.; Ciuffreda, L.P.; Costantino, S.; Morgillo, F.; Capasso, A.; Sforza, V.; Nappi, A. Increased TGF- $\alpha$ as a mechanism of acquired resistance to the anti-EGFR inhibitor cetuximab through EGFR-MET interaction and activation of MET signalling in colon cancer cells. Clin. Cancer Res. 2013, 19, 6751-6765.

26. Bardelli, A.; Corso, S.; Bertotti, A.; Hobor, S.; Valtort, E.; Siravegna, G.; Sartore-Bianchi, A.; Scala, E.; Cassingena, A.; Zecchin, D. Amplification of the MET receptor drives resistance to anti-EGFR therapies in colorectal cancer. Cancer Discov. 2013, 3, 658-673.

27. Sulpice, E.; Ding, S.; Muscatelli-Groux, B.; Bergé, M.; Han, Z.C.; Plouet, J.; Tobelem, G.; Merkulova-Rainon, T. Cross-talk between the VEGF-a and HGF signalling pathways in endothelial cells. Biol. Cell 2009, 101, 525-539.

28. Vermeulen, L.; de Sousa E Melo, F.; van der Heijden, M.; Cameron, K.; de Jong, J.H.; Borovski, T.; Tuynman, J.B.; Todaro, M.; Merz, C.; Rodermond, H. Wnt activity defines colon cancer stem cells and is regulated by the microenvironment. Nat. Cell Biol. 2010, 12, 468-476.

29. Huh, C.G.; Factor, V.M.; Sánchez, A.; Uchida, K.; Conner, E.; Thorgeirsson, S.S. Hepatocyte growth factor/c-MET signalling pathway is required for efficient liver regeneration and repair. Proc. Natl. Acad. Sci. USA 2004, 101, 4477-4482.

30. You, H.; Ding, W.; Dang, H.; Jiang, Y.; Rountree, C.B. C-MET represents a potential therapeutic target for personalised treatment in hepatocellular carcinoma. Hepatology 2011, 54, 879-889.

31. Kalluri, R.; Weinberg, R.A. The basics of epithelial-mesenchymal transition. J. Clin. Investig. 2009, 119, 1420-1428.

32. Ding, W.; You, H.; Dang, H.; LeBlanc, F.; Galicia, V.; Lu, S.C.; Stiles, B.; Rountree, C.B. Epithelial-to-mesenchymal transition of murine liver tumour cells promotes invasion. Hepatology 2010, 52, 945-953.

33. Eathiraj, S.; Palma, R.; Volckova, E.; Hirschi, M.; France, D.S.; Ashwell, M.A.; Chan, T.C. Discovery of a novel mode of protein kinase inhibition characterised by the mechanism of inhibition of human c-MET protein autophosphyrlation by ARQ 197. J. Biol. Chem. 2011, 286, 20666-20676.

34. Munshi, N.; Jeay, S.; Li, Y.; Chen, C.R.; France, D.S.; Ashwell, M.A.; Hill, J.; Moussa, M.M.; Leggett, D.S.; Li, C.J. ARQ 197, a novel and selective inhibitor of the human c-MET receptor tyrosine kinase with antitumour activity. Mol. Cancer Ther. 2010, 9, 1544-1553.

35. Rosen, L.S.; Senzer, N.; Mekhail, T.; Ganapathi, R.; Chai, F.; Savage, R.; Waghorne, C.; Abbadessa, G.; Schwartz, B.; Dreicer, R. A phase I dose-escalation study of tivantinib (ARQ 197) in adult patients with metastatic solid tumors. Clin. Cancer Res. 2011, 17, 7754-7764. 
36. Yap, T.A.; Olmos, D.; Brunetto, A.T.; Tunariu, N.; Barriuso, J.; Riisnaes, R.; Pope, L.; Clark, J.; Futreal, A.; Germuska, M. Phase I trial of a selective c-MET inhibitor ARQ 197 incorporating proof of mechanism pharmacodynamic studies. J. Clin. Oncol. 2011, 29, 1271-1279.

37. Yamamoto, N.; Murakami, H.; Nishina, T.; Hirashima, T.; Sugio, K.; Muro, K.; Takahashi, T.; Naito, T.; Yasui, H.; Akinaga, S. The effect of CYP2C19 polymorphim on the safety, tolerability, and pharmacokinetics of tivantinib (ARQ 197): Results from a phase I trial in advanced solid tumours. Ann. Oncol. 2013, 24, 1653-1659.

38. Camacho, L.H.; Bendell, J.C.; John-Reid, L.; Campos, L.T.; Jones, S.F.; Kazakin, J.; Savage, R.; Schwartz, B.E.; Abbadessa, G.; Saleh, M.N. Phase Ib dose-escalation trial evaluating c-MET inhibitor ARQ 197 administered in combination with gemcitabine to patients with advanced solid tumours. J. Clin. Oncol. 2010, 28 (Suppl. S15), e13008.

39. Goldman, J.W.; Laux, I.; Chai, F.; Savage, R.E.; Ferrari, D.; Garmey, E.G.; Just, R.G.; Rosen, L.S. Phase 1 dose-escalation trial evaluation the combination of the selective MET inhibitor tivantinib (ARQ 197) plus erlotinib. Cancer 2012, 118, 5903-5911.

40. Puzanov, I.; Sosman, J.; Santoro, A.; Saif, M.W.; Goff, L.; Dy, G.K.; Zucali, P.; Means-Powell, J.A.; Ma, W.W.; Simonelli, M. Phase 1 trial of tivantinib in combination with sorafenib in adult patients with advanced solid tumors. Investig. New Drugs 2015, 33, 159-168.

41. Santoro, A.; Simonelli, M.; Rodriguez-Lope, C.; Zucali, P.; Camacho, L.H.; Granito, A.; Senzer, N.; Rimassa, L.; Abbadessa, G.; Schwartz, B. A phase-1b study of tivantinib (ARQ 197) in adult patients with hepatocellular carcinoma and cirrhosis. Br. J. Cancer 2013, 108, 21-24.

42. Chen, C.R.; Szwaya, J.; Rojnuckarin, A.; Uppalapati, U.; Huang, L.; Nakuci, E.; Cornell-Kennon, S.; Brown, J.; McSweeney, D.; Bruseo, C. Combination studies of tyrosine kinase inhibitors (TKIs): Assessment of potential cytotoxic synergy of ARQ 197 with sorafenib or sunitinib. Cancer Res. 2009, 69, 18-22.

43. Chai, F.; Abbadessa, G.; Savage, R.; Zahir, H.; Chen, Y.; Lamar, M.; Kazakin, J.; Ferrari, D.; von Roemeling, R.; Schwartz, B. Phase 1 experience of tivantinib in patients with hepatocellular carcinoma (HCC) or biliary tract cancer (BTC). Ann. Oncol. 2012, 23 (Suppl. S9), 245.

44. Rimassa, L.; Personeni, N.; Simonelli, M.; Santoro, A. Tivantinib: A new promising mesenchymal-epithelial transition factor inhibitor in the treatment of hepatocellular carcinoma. Futur. Oncol. 2013, 9, 153-165.

45. Santoro, A.; Porta, C.; Rimassa, L.; Borbath, I.; Daniele, B.; Finn, R.S.; Raoul, J.L.; Schwartz, L.H.; He, A.R.; Trojan, J.J. Metiv-HCC: A phase III clinical trial evaluating tivantinib (ARQ 197), a MET inhibitor, versus placebo as second-line in patients with MET-high inoperable hepatocellular carcinoma. J. Clin. Oncol. 2013, 31 (Suppl. S15), TPS4159.

46. Rimassa, L.; Porta, C.; Borbath, I.; Daniele, B.; Finn, R.S.; Raoul, J.L.; Schwartz, L.H.; He, A.R.; Trojan, J.; Peck-Radosavlijevic, M. Tivantinib in MET-high hepatocellular carcinoma patients and the ongoing phase III clinical trial. Hepatic Oncol. 2014, 1, 181-188.

47. Xiang, Q.; Chen, W.; Ren, M.; Wang, J.; Zhang, H.; Deng, D.; Zhang, L.; Shang, C.; Chen, Y. Cabozantinib suppresses tumor growth and metastasis in hepatocellular carcinoma by a dual blockade of VEGFR2 and MET. Clin. Cancer Res. 2014, 20, 2959-2970. 
48. Kurzrock, R.; Sherman, S.I.; Ball, D.W.; Forastiere, A.A.; Cohen, R.B.; Mehra, R.; Pfister, D.G.; Cohen, E.E.; Janisch, L.; Nauling, F. Activity of XL 184 (cabozantinib), an oral tyrosine kinase inhibitor, in patients with medullary thyroid cancer. J. Clin. Oncol. 2011, 29, 2660-2666.

49. Gordon, M.S.; Vogelzang, N.J.; Schoffski, P.; Daud, A.; Spira, A.I.; O’Keeffe, B.A.; Rafferty, T.; Lee, Y.; Berger, R.; Shapiro, G. Activity of cabozantinib (XL 184) in soft tissue and bone: Results of a phase II randomised discontinuation trial (RDT) in patients (pts) with advanced solid tumors. J. Clin. Oncol. 2011, 29 (Suppl. S15), Abstract 3010.

50. Cohn, A.L.; Kelley, R.K.; Yang, T.S.; Su, W.C.; Verslype, C.; Ramies, D.A.; Lee, Y.; Shen, X.; Cutsem, E.V. Activity of cabozantinib (XL184) in hepatocellular carcinoma patients (pts): Results from a phase II randomized discontinuation trial (RDT). J. Clin. Oncol. 2012, 30 (Suppl. S4), Abstract 261.

51. Lu, K.V.; Chang, J.P.; Parachoniak, C.A.; Pandika, M.M.; Aghi, M.K.; Meyronet, D.; Isachenko, N.; Fouse, S.D.; Phillips, J.J.; Cheresh, D.A. VEGF inhibits tumour cell invasion and mesenchymal transition through a MET-VEGFR2 complex. Cancer Cell 2012, 22, 21-35.

52. Abou-Alfa, G.K.; Cheng, A.; Meyer, T.; El-Khoueiry, A.B.; Ikeda, M.; Chun, H.G.; Faivre, S.J.; Furuse, J.; Knox, J.J.; Okusaka, T. Phase 3 randomized, double-blind, controlled study of cabozantinib (XL 184) versus placebo in subjects with hepatocellular carcinoma who have received prior sorafenib (CELESTIAL; NCT01908426). J. Clin. Oncol. 2014, 32 (Suppl. S15), Abstract TPS4150.

53. Liu, X.; Wang, Q.; Yang, G.; Marando, C.; Koblish, H.K.; Hall, L.M.; Fridman, J.S.; Behshad, E.; Wynn, R.; Li, Y. A novel kinase inhibitor INCB28060 blocks c-MET-dependent signalling, neoplastic activities, and crosstalk with EGFR and HER-3. Clin. Cancer Res. 2011, 17, 7127-7138.

54. Bang, Y.J.; Su, W.C.; Nam, D.H.; Lim, W.T.; Bauer, T.M.; Brana, I.; Poon, R.T.P.; Hong, D.S.; Lin, C.C.; Peng, B. Phase I study of the safety and efficacy of INC280 in patients with advanced MET-dependent solid tumours. J. Clin. Oncol. 2014, 32 (Suppl. S15), Abstract 2520.

55. Bladt, F.; Friese-Hamim, M.; Ihling, C.; Wilm, C.; Blaukat, A. The c-MET inhibitor MSC2156119J effectively inhibits tumor growth in liver cancer models. Cancers 2014, 19, 1736-1752.

56. Falchook, G.S.; Hong, D.S.; Amin, H.M.; Fu, S.; Piha-Paul, S.A.; Janku, F.; Granda, J.G.; Zheng, H.; Klevesath, M.B.; Kohler, K. Results of the first-in-human phase I trial assessing MSC2156119J (EMD 1214063), an oral selective c-MET inhibitor, in patients with advanced solid tumours. J. Clin. Oncol. 2014, 32 (Suppl. S15), Abstract 2521.

57. Qin, S.; Cheng, A.L.; Lim, H.Y.; Xu, L.; Bladt, F.; Johne, A.; Li, C.; Zheng, H.; Massimini, G. A multicentre, randomised, phase $\mathrm{Ib} / \mathrm{II}$ trial of the oral c-MET inhibitor MSC2156119J as monotherapy versus sorafenib in Asian patients with MET-positive advanced hepatocellular carcinoma and Child-Pugh A liver function. J. Clin. Oncol. 2014, 32 (Suppl. S15), Abstract TPS4151.

58. Huynh, H.; Ong, R.; Soo, K.C. Foretinib demonstrates anti-tumour activity and improves overall survival in preclinical models of hepatocellular carcinoma. Angiogenesis 2012, 15, 59-70.

59. Eder, J.P.; Shapiro, G.I.; Appleman, L.J.; Zhu, A.X.; Miles, D.; Keer, H.; Cancilla, B.; Chu, F.; Hitchcock-Bryan, S.; Sherman, L. A phase I study of foretinib, a multi-targeted inhibitor of c-MET and vascular endothelial growth factor receptor 2. Clin. Cancer Res. 2010, 16, 3507-3516.

60. Yau, T.C.; Sukeepaisarnjaroen, W.; Chao, Y.; Yen, C.J.; Lausoontornsiri, W.; Chen, P.J.; Sanpajit, T.; Lencioni, R.; Camp, A.C.; Cox, D.S. A phase I/II study of foretinib, an oral multikinase inhibitor 
targeting MET, RON, AXL, TIE-2, and VEGF in advanced hepatocellular carcinoma (HCC). J. Clin. Oncol. 2012, 30 (Suppl. S15), Abstract 4108.

61. Nakagawa, T.; Tohyama, O.; Yamaguchi, A.; Matsushima, T.; Takahashi, K.; Funasaka, S.; Shirotori, S.; Asada, M.; Obaishi, H. E7050: A dual c-MET and VEGFR-2 tyrosine kinase inhibitor promotes tumour regression and prolongs survival in mouse xenograft models. Cancer Sci. 2010, $101,210-215$.

62. Doi, T.; Yoshino, T.; Fuse, N.; Bando, H.; Tahara, M.; Ohki, M.; Fujino, M.; Nishioka, Y.; Matsuura, K.; Sawada, T. Phase I dose-finding study of golvatinib (E7050), a c-MET and EPH receptor targeted multi-kinase inhibitor, administered orally bid to patients with advanced solid tumors. J. Clin. Oncol. 2012, 30 (Suppl. S15), Abstract 3079.

63. Molife, L.R.; Dean, E.J.; Blanco-Codesido, M.; Krebs, M.G.; Brunetto, A.T.; Greystoke, A.P.; Daniele, G.; Lee, L.; Kuznetsov, G.; Myint, K.T. A phase I, dose-escalation study of the multitargeted receptor tyrosine kinase inhibitor, golvatinib, in patients with advanced solid tumors. Clin. Cancer Res. 2014, 20, 6284-6294.

64. O’Neil, B.H.; Bendell, J.C.; Modiano, M.R.; Machiels, J.P.H.; Versola, M.J.; Hodge, J.P.; Sawarna, K.; Tse, N. Phase I/II study of E7050 (golvantinib) in combination with sorafenib in patients (pts) with advanced hepatocellular carcinoma (HCC): Phase I results. J. Clin. Oncol. 2013, 31 (Suppl. S4), Abstract 294.

65. Merchant, M.; Ma, X.; Maun, H.R.; Zheng, Z.; Peng, J.; Romero, M.; Huang, A.; Yang, N.Y.; Nishimura, M.; Greve, J. Monovalent antibody design and mechanism of action of onartuzumab, a MET antagonist with anti-tumor activity as a therapeutic agent. Proc. Natl. Acad. Sci. USA 2013, 110, E2987-E2996.

66. Mai, E.; Zheng, Z.; Chen, Y.; Peng, J.; Severin, C.; Filvaroff, E.; Romero, M.; Mallet, W.; Kaur, S.; Gelzleichter, T. Nonclinical evaluation of the serum pharmacodynamic biomarkers HGF and shed MET following dosing with the anti-MET monovalent monoclonal antibody onartuzumab. Mol. Cancer Ther. 2014, 13, 540-552.

67. Salgia, R.; Patel, P.; Bothos, J.; Yu, W.; Eppler, S.; Hegde, P.; Bai, S.; Kaur, S.; Nijem, I.; Catenacci, D.V. Phase I dose-escalation study of onartuzumab as a single agent and in combination with bevacizumab in patients with advanced solid malignancies. Clin. Cancer Res. 2014, 20, 1666-1675.

68. Nishio, M.; Horiike, A.; Nokihara, H.; Horinouchi, H.; Nakamichi, S.; Wakui, H.; Ohyanagi, F.; Kudo, K.; Yanagitani, N.; Takahashi, S. Phase I study of the anti-MET antibody onartuzumab in patients with solid tumors and MET-positive lung cancer. Investig. New Drugs 2015, 33, 632-640.

69. Liu, L.; Zeng, W.; Wortinger, M.A.; Yan, S.B.; Cornwell, P.; Peek, V.L.; Stephens, J.R.; Tetreault, J.W.; Xia, J.; Manro, J.R. LY2875358, a neutralizing and internalizing anti-MET bivalent antibody, inhibits HGF-dependent and HGF-independent MET activation and tumor growth. Clin. Cancer Res. 2014, 20, 6059-6070.

70. Goldman, J.W.; Rosen, L.S.; Algazi, A.P.; Tumer, P.K.; Wacheck, V.; Tuttle, J.; Wooldrige, J.E.; Banck, M.S. First-in-human dose escalation study of LY2875358 (LY), a bivalent MET antibody, as monotherapy and in combination with erlotinib (E) in patients with advanced cancer. J. Clin. Oncol. 2013, 31 (Suppl. S15), Abstract 8093. 
71. Peters, S.; Adjei, A.A. MET: A promising anticancer therapeutic target. Nat. Rev. Clin. Oncol. 2012, 9, 314-326.

72. Sierra, J.R.; Tsao, M.S. C-MET as a potential therapeutic target and biomarker in cancer. Ther. Adv. Med. Oncol. 2011, 3 (Suppl. S1), S21-S35.

73. Spigel, D.R.; Ervin, T.J.; Ramlau, R.; Daniel, D.B.; Goldschmidt, J.H.; Blumenschein, G.R.; Krzakowski, M.J.; Robinet, G.; Clement-Duchene, C.; Barlesi, F. Final efficacy results from OAM4558g, a randomised phase II study evaluating MetMAb or placebo in combination with erlotinib in advanced NSCLC. J. Clin. Oncol. 2011, 29 (Suppl. S15), Abstract 7505.

74. Iveson, T.; Donehower, R.C.; Davidenko, I.; Tjulandin, S.; Deptala, A.; Harrison, M.; Nirni, S.; Lakshmaiah, K.; Thomas, A.; Jiang, Y. Rilotumumab in combination with epirubicin, cisplatin, and capecitabine as first-line treatment for gastric or oesophagogastric junction adenocarcinoma: An open-label, dose de-escalation phase $1 \mathrm{~b}$ study and a double-blind, randomised phase 2 study. Lancet Oncol. 2014, 15, 1007-1018.

75. Venepalli, N.K.; Goff, L. Targeting the HGF-cMET axis in hepatocellular carcinoma. Int. J. Hepatol. 2013, 2013, 341636.

76. Bellon, S.F.; Kaplan-Lefko, P.; Yang, Y.; Zhang, Y.; Moriguchi, J.; Rex, K.; Johnson, C.W.; Rose, P.E.; Long, A.M.; O’Connor, A.B. C-MET inhibitors with novel binding mode show activity against several hereditary papillary renal cell carcinoma-related mutations. J. Biol. Chem. 2008, 283, 2675-2683.

77. Berthou, S.; Aebersold, D.M.; Schmidt, L.S.; Stroka, D.; Heigl, C.; Streit, B.; Stalder, D.; Gruber, G.; Liang, C.; Howlett, A.R. The MET kinase inhibitor SU11274 exhibits a selective inhibition pattern toward different receptor mutated variants. Oncogene 2004, 8, 5387-5393.

78. Shah, M.A.; Wainberg, Z.A.; Catenacci, D.V.; Hochster, H.S.; Ford, J.; Kunz, P.; Lee, F.C.; Kallender, H.; Cecchi, F.; Rabe, D.C. Phase II study evaluating 2 dosing schedules of oral foretinib (GSK1363089), CMET/VEGFRr2 inhibitor, in patients with metastatic gastric cancer. PLoS ONE 2013, 8, e54014.

79. Sequist, L.V.; von Pawel, J.; Garmey, E.G.; Akerley, W.L.; Brugger, W.; Ferrari, D.; Chen, Y.; Costa, D.B.; Gerber, D.E.; Orlov, S. Randomized phase II study of erlotinib plus tivantinib versus erlotinib plus placebo in previously treated non-small-cell lung cancer. J. Clin. Oncol. 2011, 29, $3307-3315$.

(C) 2015 by the authors; licensee MDPI, Basel, Switzerland. This article is an open access article distributed under the terms and conditions of the Creative Commons Attribution license (http://creativecommons.org/licenses/by/4.0/). 